\title{
Escolas Multisseriadas: a experiência internacional e reflexões para o caso brasileiro
}

Cláudia da Mota Darós Parente*

\section{Resumo}

O estudo sistematiza pesquisas e experiências sobre a multisseriação em países desenvolvidos e em desenvolvimento, por meio de uma revisão da literatura internacional, analisando suas opções político-pedagógicas. Evidencia-se que a multisseriação, no caso brasileiro, é resultado de uma necessidade e não uma opção pedagógica. Porém, a multisseriação proveniente de uma necessidade deve avançar para a busca de alternativas pedagógicas. Compreendendo a multidirecionalidade das opções político-pedagógicas em qualquer forma de organização escolar, defendemos que a política educacional brasileira deve abdicar da simples negação à multisseriação, buscando investigar experiências e investir na construção de alternativas que garantam o acesso à educação de qualidade a todos.

Palavras-chave: Escola Multisseriada. Política Educacional. Educação do Campo.

\section{Introdução}

O presente estudo tem a intenção de discorrer sobre o tema da multisseriação, trazendo à tona questionamentos relativos aos seus aspectos político-pedagógicos, chamando a atenção para seus vínculos diretos com a organização dos tempos e espaços educativos ${ }^{1}$. Optamos por fazer essa discussão por meio de uma revisão da literatura internacional sobre as escolas multisseriadas, as multigrade schools, propiciando condições de melhor compreender as opções desencadeadas nas últimas décadas em diferentes países e analisando os limites das políticas e legislações no âmbito da multisseriação.

Historicamente, a população do campo esteve à margem da educação escolar². A democratização da educação, possibilitando o acesso à educação a todos, trouxe à tona a discussão referente ao tipo de escola construída para atender a demandas reduzidas em localidades distantes e/ou isoladas. Nesse espaço e contexto nasceu e se disseminou a chamada multisseriação ${ }^{3}$.

\footnotetext{
Doutora em Educação, Unicamp. Professora Adjunta da Universidade Federal de Sergipe. e-mail: claudiadaros@hotmail.com.

1 A questão dos tempos escolares associada aos tempos dos sujeitos educativos é tratada por Parente (2006).

2 O movimento da Educação do Campo, no Brasil, é retratado por Arroyo, Caldart e Molina (2009).

3 A multisseriação pode ocorrer em espaços rurais e urbanos e em meio a várias demandas e intenciona-
} 
A escola multisseriada, como opção de organização que atende a um número reduzido de sujeitos, num espaço pequeno e com poucos profissionais, pode ser caracterizada como política de democratização do acesso à educação, ainda que tenha relegado a segundo plano as necessárias opções pedagógicas.

Poder-se-ia criar uma escola com cinco níveis/graduações diferentes para atendimento no primeiro segmento do Ensino Fundamental, no caso brasileiro, com professores específicos para cada faixa etária/ano escolar, atendendo cerca de 1 a 5 alunos em cada série/ano/turma. Melhor ainda: poder-se-ia criar uma escola cuja preocupação central com os sujeitos educativos viesse a superar as imposições das padronizações e seriações promovidas nas escolas urbanas.

Diante da inexistência de um projeto pedagógico para as escolas ditas "isoladas", projeto esse que ultrapassasse as barreiras burocráticas da designação de alunos para séries específicas, optou-se pela adequação do modelo seriado urbano nas escolas "isoladas". Essa opção política está diretamente associada à questão dos investimentos educacionais. Os custos de implantação do modelo seriado em sua completude (idade-série) em tais escolas seriam muito altos. Por isso, a opção foi de fazer a junção de grupos de alunos de diferentes faixas etárias, matriculados em diferentes séries/anos, com um único professor, todos num mesmo espaço.

Na educação brasileira, não é incomum, quando o tema da multisseriação vem à tona, nos depararmos com a defesa equivocada de seu contrário, a seriação $0^{4}$. É a compreensão errônea de que a escola multisseriada passaria necessariamente por um processo evolutivo, culminando na seriação, estágio mais avançado de organização da instituição escolar. Se pensarmos nas opções políticas em meio às quais nasceu a multisseriação, há certa lógica nessa abordagem. Mas, se pensarmos na própria crise do modelo seriado, desejar que o falacioso processo evolutivo da escola ocorra, será retroceder e negar as próprias oportunidades que surgem cotidianamente nas escolas multisseriadas, apesar do fardo nominal que carregam, apesar da ausência de políticas públicas para as populações do campo, apesar da demora em tratar os sujeitos dessas escolas como agentes na construção social da escola.

A multisseriação é uma prática que incomoda. E vem incomodando cada vez mais porque é a partir dela que são expostos muitos dos históricos problemas

4 Sobre a seriação, histórico e características, indicamos Freitas (2003). 
educacionais: escassa infraestrutura material, pedagógica, administrativa e de recursos humanos; condições precárias de trabalho e de formação docente. Esses problemas são retratados no trabalho organizado por Hage (2005) e nas várias experiências apresentadas por Hage e Antunes-Rocha (2010).

A multisseriação traz à tona outros temas como: direito à educação, sua democratização, seu acesso, sucesso do aluno, qualidade educacional, organização do trabalho pedagógico, currículo, formação docente, diversidade e projeto político-pedagógico. Temas tão debatidos na atualidade, mas muitas vezes vazios de significações, desprovidos de relação com os sujeitos da educação.

Se a multisseriação incomoda, sua pura e simples negação também. Por que o desejo de eliminá-la? Por que considerá-la como causa de todas as mazelas existentes nas escolas que a adotam? Por que ela tem sido vista como vilã no alcance dos objetivos educacionais? Quais são os reais limites e possibilidades da organização da escolarização em multisséries? Será que tais incômodos não estão associados à própria lógica que ela recebeu de herança e às dificuldades de se romper com o paradigma da seriação e construir outras formas de organização que deem conta do processo educativo no âmbito da escola?

Entendemos que a organização da escolarização em multisséries é parte da opção do sistema de ensino que a adota. Compreendemos que as opções pedagógicas, seja numa organização multisseriada, seriada ou outra qualquer, são feitas também no cotidiano da prática educativa, no currículo em movimento, no contexto do planejamento do professor, nas várias transgressões docentes, tornando as barreiras da seriação ou da multisseriação mais ou menos intransponíveis, a depender das escolhas que são feitas. Acreditamos, portanto, na existência da multidirecionalidade das opções político-pedagógicas em qualquer forma de organização escolar.

Quando um sistema de ensino opta pela multisseriação em algumas escolas e turmas, em muitos casos tal opção não vem associada a um conjunto de orientações pedagógicas. Não são dadas ao professor, na maioria das vezes, orientações de como atuar numa organização multisseriada. Essa ausência de orientação leva, muitas vezes, a reproduções do modelo seriado na própria multissérie, o que acarreta trabalhos duplicados ou, até mesmo, quintuplicados, tendo em vista a junção de alunos matriculados em diferentes séries/anos. 
Por outro lado, a ausência de orientação pedagógica aos professores da multisseriação abre espaço para a busca de soluções pedagógicas nascidas no cotidiano do fazer-docente; abre espaço para a criação de alternativas, de materiais, de inovações, de novas formas de organização e de superação das adversidades surgidas no contexto educacional. Ou seja, desse ponto de vista, a organização multisseriada em nada se diferencia da organização seriada: diante de uma determinada forma de organização escolar, há uma multiplicidade de possibilidades e alternativas de atuação dos profissionais da educação, seja porque o sistema permite, seja porque ele se omite, seja porque ele é tão perverso que é preciso e necessário transgredi-lo e superá-lo política e pedagogicamente.

Ora, se a demanda pelo acesso à educação nasce do desejo de levar a escola a todos os povoados e recantos do país, esse desejo, na maioria das vezes, veio impregnado do desejo de se ter a mesma escola da cidade. E a escola da cidade é a escola seriada. Qualquer coisa que as diferencie, dadas as condições objetivas em que nascem as escolas "isoladas", é vista de forma negativa. De forma contrastante, ao longo do processo de democratização da escola, também houve espaço para o nascimento de escolas que conseguiram superar esses desejos de se igualarem à escola da cidade e que conseguiram cumprir sua função educativa sem se preocuparem em a ela se equiparar.

O fato é que o primeiro exemplo de escola acabou ganhando força e eis que a dificuldade de se igualar à escola da cidade marcou forçosamente o surgimento de um tipo de escola chamada multisseriada. Não é a escola seriada tão desejada por muitos, é um tipo de escola quase seriada, é a multisseriada.

Não é preciosismo discorrer sobre o termo. Ele está carregado de concepções e significados, repleto de elementos persuasivos, inclusive. A nomenclatura multisseriação está carregada de sentido negativo; é uma adjetivação que tem aprisionado o fazer-educativo, que tem limitado a prática pedagógica. Mais do que isso, é uma adjetivação que rotula, classifica e associa a multisseriação a um tipo de escola de baixa qualidade, fraca, difícil, trabalhosa, errada, isolada. Por que escola multisseriada e não apenas escola? É no mínimo curioso que tenhamos que adjetivar a escola multisseriada ao passo que dispensamos a adjetivação da escola "seriada".

Mas as escolas têm vida. Não são apenas resultados de políticas ou de ausência delas. Elas se criam e recriam em meio às inoperâncias burocráticas, às legislações, aos programas que começam e terminam, às lutas pelo direito à 
educação de qualidade. E é nesse contexto que surgem inovações e transgressões no cotidiano escolar. Com a escola multisseriada, esse processo não é diferente.

Apesar dos rótulos, muitas têm buscado exercer sua função sociopolítica e pedagógica; apesar do fardo, têm superado as imposições do termo, buscando romper com os encaixes e padronizações desnecessários.

Para esse estudo, utilizaremos o termo "escola multisseriada" como tradução de "multigrade school", ainda que as experiências de cada país possam carregar concepções e práticas pedagógicas diferenciadas. O termo inglês "grade" está sendo compreendido como tradução de graduação/nível, ou melhor, ano/série/idade. "Multigrade", portanto, como multissérie/multiidade/multigraduado. Apesar disso, ver-se-á que traduzir o termo multigrade como multissérie é significativamente diferente de traduzi-lo como multiidade, a depender de contextos específicos.

Optamos por também adjetivar a escola multisseriada neste artigo, mesmo não compactuando com a defesa de sua adjetivação. Em termos de desenvolvimento do tema e tendo em vista a necessidade de ampliação cada vez maior de pesquisas na área, compreendemos a necessidade de utilizá-lo como forma de dar voz e vez à temática. Não é mesmo uma escola qualquer; é a escola multisseriada assim denominada e construída social e historicamente. É preciso compreender o seu surgimento e analisar seus impasses para superá-los.

Essa opção é decorrente do objetivo maior deste artigo: sistematizar estudos e pesquisas que evidenciam as formas diferenciadas de organização do trabalho pedagógico em escolas que atendem sujeitos de diferentes idades/séries/anos numa mesma turma. Ou seja, diante desse quadro, quais são as opções políticopedagógicas de diferentes países, as pesquisas existentes sobre o tema e os estudos desencadeados sobre a questão no âmbito internacional.

Esperamos que esse esforço de sistematização possa produzir reflexões sobre as opções político-pedagógicas dos sistemas de ensino brasileiros em relação à multisseriação, tornando-a parte efetiva da agenda governamental e da sociedade civil, não apenas associando-a à apologia da nucleação, do fechamento de escolas ou da seriação, mas reconhecendo-a como parte de uma realidade escolar que tem vida e onde se encontram diferentes sujeitos que querem, necessitam e têm o direito de estar ali. 


\section{Escolas Multisseriadas: conceitos e características}

As escolas multisseriadas nasceram como opção política de atender a uma população historicamente excluída da escola. Tal atraso na oferta educacional é muito mais visível em países em desenvolvimento, como é o caso do Brasil. Devido a este fato, há décadas, organismos internacionais vêm discutindo e fazendo acordos de modo a superar esses atrasos históricos.

Por meio da Declaração Mundial sobre a Educação para Todos, de 1990, por exemplo, países de quase todo o mundo firmaram acordos para a universalização do ensino fundamental, com vistas a colocar em prática o que a Declaração Universal de Direitos Humanos já anunciava: toda pessoa tem direito à educação5.

Em 2000, em Dacar, os países da Organização das Nações Unidas (ONU) apresentaram os 8 Objetivos de Desenvolvimento do Milênio ou 8 jeitos de mudar o mundo ${ }^{6}$, entre eles, oferecer "educação básica de qualidade a todos". Esse objetivo é composto de 6 metas, privilegiando mais uma vez a educação primária, gratuita, de qualidade, obrigatória a todos, sem diferenças de gênero.

A Organização dos Estados Ibero-Americanos (OEI), no documento "Metas Educativas 2021 - O que queremos para a geração dos bicentenários " ", apresenta 11 metas, entre as quais, universalizar a educação básica e melhorar sua qualidade, compreendendo: escolarização mínima de 12 anos, equitativa, sem diferença de gênero, privilegiando a oferta para públicos historicamente excluídos, como os afro-descendentes e os indígenas, muitos dos quais vivem hoje no campo.

No Brasil, a Constituição de 1988 afirma a educação como direito de todos e dever do Estado e da família ${ }^{8}$. Este direito é reafirmado pelo Estatuto da Criança e do Adolescente de $1990^{9}$ e pela Lei de Diretrizes e Bases da Educação Nacional

5 Artigo XXVI da Declaração Universal dos Direitos Humanos, aprovada pela Assembléia Geral das Nações Unidas, em 10/12/1948: "Toda pessoa tem direito à instrução. A instrução será gratuita, pelo menos nos graus elementares e fundamentais. A instrução elementar será obrigatória. A instrução técnico-profissional será acessível a todos, bem como a instrução superior, esta baseada no mérito". Disponível em: http:// portal.mj.gov.br/sedh/ct/legis_intern/ddh_bib_inter_universal.htm

6 Os 8 objetivos do milênio fazem parte da Declaração do Milênio das Nações Unidas, aprovada em 08/09/2000. Disponível em: http://www.objetivosdomilenio.org.br/

7 Documento elaborado a partir de reunião dos representantes dos países iberoamericanos, em 18/05/2008. Disponível em: http://www.oei.es/metas2021.pdf.

8 Art. 205 da Constituição da República Federativa do Brasil. Disponível em: http://www.planalto.gov.br/ ccivil_03/constituicao/constitui\%C3\%A7ao.htm

9 Art. 53 da Lei n 8.090, de 13/07/1990. Disponível em: http://www.planalto.gov.br/ccivil_03/leis/l8069.htm. 
de $1996^{10}$. Mais recentemente, o Conselho Nacional de Educação aprovou duas diretrizes específicas em relação à educação do campo: Resolução CNE $n^{\circ}$ 01/2002 que estabelece as Diretrizes Operacionais para a Educação Básica das Escolas do Campo, e Resolução CNE n⿳o 02/2008 que estabelece as Diretrizes Complementares, Normas e Princípios para o Desenvolvimento de Políticas Públicas de Atendimento da Educação Básica do Campo ${ }^{11}$. Ambas afirmam o modo próprio de vida da população do campo e expõem diretrizes para a garantia da universalização do acesso, da permanência e do sucesso escolar com qualidade em todo o nível da Educação Básica para a população do campo.

É, portanto, nesse contexto político-legal, nacional e internacional, tendo em vista a implementação de políticas públicas para as escolas primárias, principalmente a partir da década de 1990, que os estudos sobre a multisseriação também começaram a se disseminar ${ }^{12}$.

A multisseriação existe tanto em países desenvolvidos como em países em desenvolvimento, tanto em zonas rurais, como em zonas urbanas. Porém, são estreitos seus vínculos com o campo e com as regiões menos povoadas.

Little (1995), uma das principais pesquisadoras da área, pertencente ao Instituto de Educação da Universidade de Londres, ressalta que o conceito de multisseriação difere a depender dos países onde é implementada. Considerando o conceito de multigrade teaching como o ensino a estudantes de diferentes idades/graus/habilidades num mesmo grupo, em contraposição ao ensino monograduado, no qual estudantes possuem idades e habilidades similares, a autora destaca que em países em desenvolvimento é possível haver grandes variações de idade num mesmo grau/ano de escolarização, tendo em vista a grande incidência da reprovação. É o que a autora denomina de "multiage-within-grade teaching". Essa situação difere significativamente da realidade dos países desenvolvidos, já que tal condição não existe.

Mais recentemente, Little (2005), ao produzir um Relatório para a UNESCO sobre a multisseriação (EFA Global Monitoring Report ${ }^{13}$ ), destaca que os sistemas, os materiais,

10 Art. $2^{\circ}$ da Lei $n^{\circ}$ 9.394, de 20 de dezembro de 1996. Disponível em: http://www.planalto.gov.br/ccivil_03/ leis/L9394.htm.

11 Resolução CNE nº 01/2002, 03/04/2002. Disponível em: http://portal.mec.gov.br/cne/arquivos/pdf/ CEB012002.pdf. Resolução CNE n 02/2008, de 28/04/2008. Disponível em: http://pfdc.pgr.mpf.gov.br/ atuacao-e-conteudos-de-apoio/legislacao/educacao/educacao-rural/resolucao_MEC_2.08

12 Cardoso e Jacomeli (2010) apresentam dados preliminares do estado da arte das escolas multisseriadas no Brasil.

13 EFA - Education for All (Educação para Todos). 
os currículos e as formações docentes são sempre pensados para as monograded schools. Ou seja, nem sempre a multisseriação faz parte da agenda política educacional. Os currículos e materiais não são pensados para atender turmas multisseriadas e, quando isso acontece, são pensados do ponto de vista de mera adequação.

Muitos professores saem dos cursos de licenciaturas sem saber da existência de turmas multisseriadas. Isso é corroborado pela evidência empírica de que os cursos de formação de professores nas várias instituições de ensino superior brasileiras sequer tratam da questão ${ }^{14}$, seja do ponto de vista político-legal, seja do ponto de vista metodológico. Essa situação poderia ser minimizada caso a formação continuada, a ser promovida pelos sistemas de ensino, garantisse aos professores em serviço as reflexões necessárias sobre a educação do e no campo, conforme preconizam as Resolução do Conselho Nacional específicas à educação do campo. (BRASIL, 2002; 2008)

Apesar disso, a multisseriação está presente em todo o mundo. Na Austrália, em 1988, 40\% das escolas dos territórios do norte eram multisseriadas. Em 1996, na Índia, $84 \%$ das escolas primárias tinham três professores ou menos. No Peru, em 1998, 78\% das escolas públicas primárias eram multisseriadas. (LITTLE, 2005)

No Brasil, existem cerca de 106 mil escolas urbanas e 107 mil escolas rurais de educação básica, atendendo aproximadamente 47 milhões de alunos e 8 milhões de alunos, na zona urbana e na zona rural, respectivamente. Na região Nordeste, são cerca de 32 mil estabelecimentos localizados na zona urbana e 61 mil na zona rural, atendendo 13 milhões e 5 milhões de alunos, respectivamente. Das 100 mil escolas rurais brasileiras de $1^{\mathrm{a}}$ a $4^{\mathrm{a}}$ do Ensino Fundamental, $70 \mathrm{mil}$ têm até 50 alunos. Do total de escolas rurais brasileiras que oferecem o ensino fundamental de $1^{\mathrm{a}}$ a $4^{\mathrm{a}}$ série, $64 \%$ são formadas, exclusivamente, por turmas multisseriadas ou unidocentes, atendendo 1 milhão e setecentos mil alunos, em turmas de aproximadamente 27 alunos (BRASIL, 2003).

Conforme aponta Little (2005), a multisseriação existe em alguns contextos, quais sejam: em escolas localizadas em regiões pouco povoadas, afastadas e/ou de difícil acesso; em escolas que compreendem um conjunto de salas de aula em várias localidades, formando um cluster; escolas localizadas em regiões cuja população está em declínio e que, inicialmente, não eram multisseriadas;

14 Tal afirmação é feita considerando-se a experiência empírica da autora como professora em cursos de licenciatura, bem como pesquisadora da área. 
escolas localizadas em regiões com crescimento populacional, com insuficiência de escolas e professores; escolas menos populares que perdem alunos para escolas mais populares; escolas que superam o número de alunos por turma, levando à criação de turmas com alunos de outro grau/série; escolas móveis (mobile schools), com um ou mais professores, cujos alunos nômades pertencem a diferentes idades/séries; escolas com alto grau de absenteísmo docente, sem professores substitutos; escolas com número real de professores abaixo do necessário; escolas que optaram pela multisseriação por razões pedagógicas.

O último motivo de existência da multisseriação (por razões pedagógicas), diferentemente dos demais, é uma escolha, ao passo que as demais nascem de uma necessidade. Para Little (2005), a multisseriação, como escolha pedagógica, é bem diferente da multisseriação num contexto de necessidade.

No caso brasileiro, dadas as suas características continentais é possível arriscar que as razões de existência da multisseriação perpassam todos os motivos apontados por Little (2005), inclusive a razão pedagógica, ainda que em menor escala.

Acreditamos que a questão central da temática é: a multisseriação é uma forma de organização da escolarização criada com base numa necessidade ou numa escolha pedagógica? No entanto, para além das duas situações expostas por Little (2005), é possível criar uma terceira situação: a multisseriação num contexto de necessidade que avança para a busca de alternativas pedagógicas ${ }^{15}$.

Little (2005) enfatiza ainda em seu relatório que, muitas vezes, a política erra no investimento em estratégias para melhorar a multisseriação em condições em que ela não deveria sequer existir. É o caso, por exemplo, de situações em que a multisseriação é utilizada em lugar de se garantir maior número de professores para a escola. Conforme a autora, "ensino multisseriado não pode ser apresentado como uma panaceia para os problemas de turmas grandes e falta de professores" ${ }^{\prime 16}$. (p. 7)

Quanto à aceitação da multisseriação, a autora destaca que, se por um lado, nos países desenvolvidos os professores têm uma percepção positiva em relação à multisseriação, por outro lado, persiste uma percepção negativa da multisseriação em países em desenvolvimento, como é o caso do Nepal e o do Peru.

15 Eis a foco da Pesquisa "Formas de Organização do Trabalho Pedagógico nas Escolas Multisseriadas de Sergipe: inovações nos tempos e espaços escolares", do qual o presente artigo é parte integrante.

16 Tradução da autora. 
No Brasil, também persiste uma visão negativa da multisseriação; não há como negar que as condições em que é implantada, sugerem haver sérios problemas relacionados à infraestrutura, ao financiamento, à gestão, à formação de professores. Em lugar de se resolverem tais questões, implanta-se a multisseriação e se aprofundam os problemas educacionais. No entanto, é possível captar, por trás das dificuldades materiais, financeiras e humanas, um desejo e uma esperança, por parte dos professores, de que existam aspectos pedagógicos positivos em escolas multisseriadas, entre os quais: trabalho em grupo, trabalho interdisciplinar, maior integração e socialização entre os estudantes, auxílio mútuo, respeito às diferenças. No entanto, cabe destacar que tais elementos não são aspectos pedagógicos "da multisseriação", mas que podem ocorrer "na multisseriação" (PARENTE; SANTANA, 2012).

Para Little (2005), são necessárias providências para que a multisseriação seja benéfica aos estudantes: 1) Aumento da sensibilização dos governantes e dos profissionais da educação em relação à multisseriação, muitos dos quais desconhecem sua natureza, características e necessidades e, a partir disso, avançar no desenvolvimento de estratégias, planejamentos, materiais e formação; 2) Adaptação curricular, considerando estratégias que veem sendo adotadas em contextos multisseriados, tais como: currículo multigraduado/ multiníveis; currículo diferenciado; quase monograduado; centrado no aluno com materiais individuais; 3) Transformação na filosofia do ensinoaprendizagem; 4) Investimento em materiais de aprendizagem, sem perder de vista a importância central e fundamental do professor na organização da aprendizagem, e atentando para o uso cuidadoso dos tradicionais livros didáticos; 5) Investimento em diferentes estratégias de organização dos alunos em sala de aula; 6) Investimento na formação de professores, seja na formação inicial, seja na formação em serviço, considerando-se os contextos multisseriados; 7) Investimento nos sistemas de avaliação com vistas a prezar a avaliação formativa e não a mera seleção.

Defende-se, portanto, uma alteração na estrutura curricular do ensino multisseriado, tendo em vista a necessidade de revisão da concepção do próprio processo de ensino-aprendizagem, alertando que isso deve ser feito em todas as turmas, escolas e países, em organização seriadas/graduadas, multisseriadas/ multi-graduada ou qualquer outra forma de organização. 
Uma abordagem mais radical no currículo tem como premissa uma mudança na filosofia de ensino-aprendizagem, de uma que enfatiza a homogeneidade dos alunos e a padronização das estratégias dos professores, para outra que reconhece a diversidade dos alunos e a necessidade de uma diferenciação nas estratégias17. (LITTLE, 2005, p. 14-15).

Pridmore (2007) apresenta um estudo sobre questões curriculares em escolas multisseriadas de vários países: Peru, Sri Lanka, Vietnã e Nepal. Tal estudo integra um Programa Internacional de Pesquisa sobre Ensino e Aprendizagem em Ambientes Multisseriados (Multigrade Settings), financiado pelo Reino Unido. A autora destaca que a grande mudança que vem acontecendo em relação à multisseriação é associá-la à possibilidade de educação para todos, tendo em vista atingir crianças que moram em localidades longínquas, bem como os custos reduzidos de manutenção de menos professores por aluno. Conforme o estudo, uma das grandes dificuldades da multisseriação é romper com a monograded norm. Isso faz com que os professores das escolas multisseriadas precisem promover adaptações.

A autora relata que, em 1998, a pesquisa sobre multisseriação desenvolvida pelo Instituto de Educação da Universidade de Londres abarcou as experiências do Vietnã, Sri Lanka e Peru e, a partir de 2002, abrangeu Nepal, Grécia, Finlândia, Espanha e Reino Unido. Após a análise das experiências observadas em diferentes países, Pridmore (2007) elenca quatro tipos de currículos existentes nas escolas multisseriadas: quase monograduado, currículo diferenciado, currículo multiidade/ciclos e currículo centrado no aluno.

O modelo quase monograduado, ou seja, o professor é responsável por um grupo de alunos pertencentes a diferentes faixas etárias/anos de escolarização e fornece atividades específicas a cada subgrupo específico, realizando atendimento diferenciado a cada um dos subgrupos em momentos específicos, como se fossem "monograduados/seriados". Esse modelo implica vários planejamentos por parte do professor.

O segundo currículo existente em escolas multisseriadas é o modelo de currículos diferenciados, uma versão do currículo quase monograduado. Neste modelo, há um tema geral tratado no começo e no fim das atividades com todos os alunos.

17 Tradução da autora. Optamos por utilizar o termo "estratégias" e não "insumos" na tradução do termo "input", de modo a aproximar o conceito da área educacional. 
Entre um momento e outro, são fornecidas atividades diferenciadas, com base em níveis de aprendizagem e/ou habilidade e com objetivos específicos, as quais são realizadas em grupo e durante as quais o professor fornece pequenas explicações aos subgrupos específicos.

O terceiro modelo curricular apresentado (multiple-year curriculum cycles) está centrado em conteúdos e objetivos específicos para cada ciclo, geralmente composto por dois anos. Este modelo é encontrado em países como Finlândia, Reino Unido, Espanha e Grécia, e está centrado no processo ${ }^{18}$.

O quarto e último modelo curricular centra-se no aluno e em materiais específicos para os alunos. É o exemplo do Programa Escuela Nueva da Colômbia. É uma adaptação do currículo monograduado, a partir da construção de um material modular. O aluno segue adiante apenas quando aprendeu a lição atual. Além da Colômbia, esse modelo é aplicado também em países como Brasil, Guatemala, Panamá, Chile, Nicarágua, Guiana, Filipinas e Uganda.

Pridmore (2007) destaca a existência de experiências nas quais há uma combinação de modelos curriculares.

No Brasil, parece haver a presença dos quatro modelos curriculares nas escolas multisseriadas, com predominância do modelo quase monograduado e do modelo centrado no aluno, este último, principalmente nas escolas multisseriadas que tiveram como herança a metodologia do Programa Escola Ativa. Tal programa, coordenado pelo Ministério da Educação, era destinado especificamente às turmas multisseriadas, teve sua origem na experiência colombiana e iniciou-se na década de 1990, deixando de existir no final de 2011, em meio a muitas críticas ${ }^{19}$. O uso do livro didático era um dos elementos principais da metodologia do Programa Escola Ativa.

Existe um grande desafio em relação à política curricular quando o assunto é multisseriação. É imprescindível considerar a multisseriação na discussão de currículos, seja na educação básica ou na educação superior. Mais do que isso: que

18 Na apresentação dos estudos de caso europeus, será possível apresentar maiores informações sobre o funcionamento de escolas que adotam este modelo curricular.

19 Muitas das críticas ao programa estão sistematizadas no documento "Nota Técnica sobre o Programa Escola Ativa: análise crítica", do Fórum Nacional de Educação do Campo, realizada em 2011. Parente, Marchelli e Santana (2011) discorrem sobre a formação de professores-multiplicadores do Programa Escola Ativa. 
na escola do campo, multisseriada ou não, as propostas pedagógicas preservem o direito à igualdade de oportunidades e garantam o respeito à diversidade do campo em todos os seus aspectos: sociais, culturais, políticos, econômicos, de gênero, geração e etnia (BRASIL, 2002).

Conforme Arroyo (2010),

A questão que se impõe é entender quais processos educativos formadores de identidades, saberes e valores estão em jogo nessa dinâmica tensa e complexa do campo. Que indagações esses processos trazem para escola do campo, para seus currículos, sua organização, para a formação e função docente-educadora. (p.11)

Afere-se, portanto, que a multisseriação é uma condição e não uma prática. Diante de uma condição é preciso rever concepções e desenvolver práticas que possibilitem que os diferentes sujeitos da educação avancem social, cultural e cognitivamente.

\section{A Multisseriação em Países Desenvolvidos: o caso europeu}

Entre os estudos que analisam a multisseriação em países desenvolvidos: Sigsworth e Solstad (2005) apresentam um estudo sobre as pequenas escolas rurais em 7 países europeus; Lemos (2001) desenvolve estudo de caso da Austrália sobre o desempenho de estudantes de turmas multisseriadas (multi-age grouping); Mariano e Kirby (2009) apresentam estudos sobre o desempenho de estudantes nos Estados Unidos ${ }^{20}$; Gordon, Lokisso e Allen (1997), analisam as single-teacher schools em 14 países desenvolvidos e em desenvolvimento, entre os quais temos, Austrália, França, Grécia e Portugal.

Para este artigo, optou-se por dar destaque ao estudo de Sigsworth e Solstad (2005), ressaltando que os países europeus pertencem à categoria daqueles que fazem da multisseriação uma escolha pedagógica. Os autores organizaram um estudo sobre as pequenas escolas rurais de 7 países europeus: Irlanda, País de Gales, Noruega, Suécia, Finlândia, Inglaterra e Islândia, considerando alguns elementos centrais, entre os quais:

20 Dois estudos têm sido muito citados pela literatura internacional quando a questão se refere a desempenho dos estudantes em turmas multisseriadas: Veenman (1995) e Mason e Burns (1996). Conforme Lemos (2001), Veenman concluiu não haver diferenças entre o desempenho de estudantes em turmas multisseriadas ou não. No entanto, Mason e Burns (1996) apontam que esse resultado pode sofrer influência pelo fato de que se oferece às escolas multisseriadas melhores e experientes professores, além de que, o tamanho reduzido da turma indica menos tempo ministrando aulas e mais tempo de preparação. Vê-se que tais conclusões não podem ser generalizadas a países em desenvolvimento, como o Brasil, cujas questões de formação e de tempo docente são secundarizadas. 
1) A vulnerabilidade das escolas rurais às decisões políticas, levando-se em conta que o modelo de escolaridade urbano é o modelo dominante e, apesar de as escolas rurais exigirem um modelo próprio, nem sempre há esforço político para tal. Com base nisso, como as escolas multisseriadas são afetadas por tais decisões políticas? 2) As escolas multisseriadas necessitam de uma organização pedagógica e curricular devido à sua especificidade, o que pode ser subestimado pelo governo e pelas políticas e diretrizes educacionais. Se as escolas multisseriadas requerem uma pedagogia e um currículo adequados, como os governos nacional e local fornecem apoio à gestão dessas escolas? 3) Um escola pequena deve fornecer um currículo igualmente complexo ao da escola urbana. É preciso captar: o governo está provendo as escolas de suporte adequado? 4) Uma turma multisseriada, supõe-se, deve ser menor do que uma turma seriada (singleage class). Há regulamentação a respeito do tamanho de uma turma multisseriada? 5) Há afirmações de que, na escola multisseriada, os alunos têm menor aprendizado do que em grandes escolas. Isso é real? A seguir serão apresentados cada um dos sete estudos citados.

O primeiro estudo, apresentado por Alwyn Evans (2005), refere-se à experiência do País de Gales. O autor aponta que, no período pré-1974, escolas foram fechadas no país no contexto do declínio da população e da economia rural. Não foi resultado de uma política específica, e sim de uma situação demográfica. Nesse período, foi publicado documento defendendo que uma escola, para ser educacionalmente viável, deveria ter no mínimo 50 alunos e três funcionários. Para o fechamento das escolas, $\mathrm{o}$ argumento da viabilidade econômica superava a questão da viabilidade do ensino. A partir de 1974 a pressão pelo fechamento das escolas foi reduzida no país. Nesse contexto, o que houve foi um processo chamado "twinning", com a junção de duas ou mais escolas, tendo um gestor responsável por ambas.

No Brasil, é possível encontrar experiências similares em sistemas de ensino que possuem as chamadas escolas-mãe, tendo um coordenador geral/diretor como responsável por um conjunto de escolas (PARENTE; SANTANA, 2012).

Evans (2005) destaca que, a partir dos anos 2000, iniciou-se uma preocupação mais política no País de Gales, estabelecendo-se documentos e critérios para uma possível reorganização das escolas ou mesmo seu fechamento. Isso foi feito com base em análises individuais das características curriculares, administrativas e pedagógicas das escolas, entre elas: 1) Proximidade em relação a outras escolas; 2) Disponibilidade de espaço nas escolas próximas; 3) Percurso para a escola; 4) Número de alunos que frequentam a escola; 5) Número de alunos previsto nos anos subsequentes. 
$\mathrm{O}$ autor apresenta alguns estudos de caso, apontando que o levantamento realizado pelo governo levou a uma reestruturação das escolas, o que implicou no fechamento de algumas, a nucleação de outras e a manutenção de muitas, ainda que com números reduzidos, tendo-se por base elementos palpáveis para cada decisão. Cita o caso de escolas cujos próprios pais decidiram pelo fechamento e preferiram o fornecimento do transporte.

A experiência brasileira mostra que a decisão pelo fechamento das escolas "isoladas", escolas dos povoados, escolas dos distritos está sendo tomada, na sua maior parte, sem a consulta à comunidade (FAGUNDES; MARTINI, 2003), o que contraria as próprias diretizes para a educação do campo. (BRASIL, 2008)

No segundo estudo europeu, Ingrid Sörlin (2005) faz referência às escolas paroquiais ou escolas populares surgidas na segunda metade do século XIX, na Suécia. A autora destaca que, nessa época, surgiram as pequenas escolas populares, com menor qualidade e com professores não certificados, de modo a atender a população. $\mathrm{Na}$ década de 1950, as monograde schools eram chamadas de A-schools e as multigrade schools de $B$-schools. Conforme a autora, a definição de pequena escola rural é "uma escola rural com no máximo 50 alunos entre 6 e 13 anos". (p. 18) 11 $^{21}$

O final da década de 1990 foi marcado pelo fechamento de muitas escolas. As 1.065 small schools existentes em 1974, passaram a $600 \mathrm{em} \mathrm{1997.} \mathrm{O} \mathrm{fechamento} \mathrm{ocorreu}$ devido à diminuição da demanda, à migração das famílias para a cidade em busca de trabalho e ao declínio da taxa de natalidade, bem como a problemas financeiros para a manutenção das pequenas escolas. A autora alerta que o fechamento de escolas não pode ser visto apenas como economia de recursos financeiros. É preciso investigar as consequências dessa decisão política. Isso porque a escola tem grande importância para a comunidade; é parte central de sua infra estrutura, centro de aprendizagem para todas as idades, um village meeting place, ou seja, um lugar de encontro da comunidade. A autora cita trecho de uma conferência de Jan Cedevärn, na Interskola ${ }^{22}$, em 2003, o qual destaca que a village school deve ser o centro da vila não apenas fisicamente, mas também na consciência das pessoas.

21 Tradução da autora.

22 Interskola é o nome de uma Conferência Anual que teve início em 1968, na Escócia. Originou-se do encontro de professores de áreas rurais da Noruega e da Escócia, em 1967. A 44 Conferência Interskola aconteceu no Kenia, em 2011. Foi a primeira vez em que foi realizada fora da Europa. Participam da Conferência representantes de vários países do mundo. A Interskola Network (Interskola - Educacion in Remote and Rural Communities) tem como foco, entre outros, a educação em áreas rurais e pouco povoadas. Conforme: www.interskola.net 
Conforme a autora, os defensores das small schools acreditam que esse tipo de escola ganha em proximidade com a comunidade, além de garantir um ensino-aprendizagem mais individualizado. Outros críticos afirmam que o aprendizado nessas escolas não possui tanta qualidade como nas grandes escolas. Apesar disso, a autora relata pesquisa em que demonstra não haver diferença de desempenho dos alunos no que se refere à variável "tamanho de escola". No entanto, é clara a dificuldade da small village school em termos de distância das decisões políticas, porém, a mesma parece encontrar soluções criativas para seus problemas. $\mathrm{O}$ estudo demonstra que, apesar da antipatia existente em relação às pequenas escolas, onde a norma é o multigrade teaching, o método de ensino com alunos de diferentes idades (mixed age groups), entre 6 e 9 anos, tornou-se tendência também em grandes escolas.

O terceiro estudo europeu apresentado refere-se à Irlanda. Mulryan-Kyne (2005) destaca que as "small one or two-teacher schools" foram, historicamente, a principal característica das escolas primárias do país. A partir da década de 1960, o fechamento das escolas e as fusões (amalgamation) basearam-se no argumento da natalidade, da urbanização e do declínio da população.

Nos anos de 1990, a política governamental irlandesa induziu à manutenção de pequenas escolas, contanto que tivessem o mínimo de quatro professores. Conforme dados de 2003, na Irlanda, 49\% dos alunos do ensino primário estavam matriculados em pequenas escolas e $42 \%$ dos professores do ensino primário estavam nestas escolas.

$\mathrm{Na}$ Irlanda, escolas com até 12 alunos têm direito a um professor; de 12 a 50 alunos, dois professores; de 50 a 82 alunos, 3 professores; de 82 a 116 alunos, 4 professores. Nas escolas até 180 alunos e com até 8 professores (75\% das escolas primárias do país), o diretor da escola é também um professor.

Em termos de formação, não há cursos específicos para os professores que trabalham nas multigrade schools. No entanto, a multisseriação é tratada na maior parte dos cursos de formação de professores como parte da metodologia e dos currículos.

No que se refere ao desempenho dos alunos, a autora faz referência à pesquisa que demonstra a inexistência de diferenças significativas associadas ao tamanho da escola no que se refere ao aprendizado do irlandês e do inglês, quando comparadas crianças de multigrade-classes e single-grade classes. 
Conforme Mulryan-Kyne (2005), a maioria dos professores sente-se satisfeita em trabalhar com a multigrade class. No entanto, alguns problemas existentes são destacados: o ensino na multigrade class requer maior organização e gestão do que a single-grade class e, por isso, sentem dificuldade de atender a todas as exigências de escolarização; o fato de muitos professores acumularem funções também de diretores prejudica o ensino; a distância e o isolamento das escolas também é um fator prejudicial, inibindo a participação em eventos esportivos do país ou o acesso a serviços de apoio psicológico, por exemplo.

No quarto estudo europeu apresentado, Syväniemi (2005) informa que, na Finlândia, não há regulamentação no que se refere ao número mínimo de alunos e professores por turma/escola. Conforme o autor, em termos de rendimento, os alunos das small schools possuem rendimento igual ao dos alunos das large schools. Além disso, como espaço para a aprendizagem social, as pequenas escolas são melhores do que as grandes escolas.

Como problemas, as pequenas escolas da Finlândia apresentam questões relativas à diminuição dos alunos, o que pode levar ao fechamento das escolas. Além disso, é necessário investir na qualificação dos professores que atuam nas escolas. $\mathrm{Na}$ Inglaterra, conforme Tony Rule (2005), que apresenta o quinto estudo europeu, as escolas localizadas no campo ou, education in the countryside, desde a sua existência, a partir de 1870, sempre foram organizadas com multigraded classes para as crianças de 5 a 14 anos.

A Lei da Educação de 1944 organizou o ensino inglês da seguinte forma: primário (5-11 anos) e secundário (11-15/16/18). Entre as décadas de 1960 e 1980, as pequenas escolas perderam alunos e muitas foram fechadas.

Durante o mandato da primeira ministra Thatcher ${ }^{23}$, definiu-se que 9 seria o número mínimo de professores para o funcionamento de uma pequena escola. Tal determinação subsidiou os desejos de muitos governantes em fechar ou nuclear (amalgamate) escolas.

No Brasil, a temática da multisseriação está estreitamente vinculada à questão da nucleação. Isto porque, a multisseriação é apresentada como decisão política para não nuclear as escolas. Por sua vez, a política de fechamento de escolas rumo à nucleação tem sido adotada em muitos sistemas de ensino, sob o argumento

23 Margaret Thatcher foi primeira ministra do Reino Unido de 1979 a 1990. 
financeiro, com vistas a reduzir os custos de manutenção de uma escola com poucos alunos e sob o argumento dito "pedagógico", com vistas a eliminar a multisseriação. Ou seja, em muitos sistemas de ensino, as opções apresentadas são: multisseriar para não nuclear; nuclear para não multisseriar. Essas práticas ocorrem em meio ao silenciamento das diretrizes da educação do campo, as quais estabelecem que a educação infantil e os anos iniciais do ensino fundamental "sempre serão oferecidos nas próprias comunidades rurais, evitando-se os processos de nucleação de escolas e de deslocamento das crianças", admitindo-se, excepcionalmente que os anos iniciais do ensino fundamental "poderão ser oferecidos em escolas nucleadas, com deslocamento intracampo dos alunos" (BRASIL, 2008).

Conforme Carvalho et al (2010, p. 291)

O processo de nucleação nas redes municipais reduziu o número de escolas nas comunidades do campo. Isso foi revelado pelos participantes nos ciclos de diálogos. Eles lamentavam o fato, argumentando que, ao fechar uma escola, a vida das comunidades ficava altamente comprometida. Primeiro, porque a escola é ainda o único equipamento público na maioria das comunidades rurais; segundo, porque o deslocamento das crianças para outras comunidades estimulava os pais a abandonarem suas propriedades para acompanhar seus filhos e, assim, garantir-lhes a escolarização.

No que se refere à experiência inglesa, em 1995, o governo reconheceu a escola do campo como importante para a localidade. Tal ideia fortaleceu-se diante da constatação de que não havia diferenças entre a pequena e a grande escola, após a aplicação de instrumentos de medição do desempenho dos alunos.

Rule (2005) destaca a região da Cornualha (Cornwall) como um caso específico da Inglaterra, tecendo maiores considerações sobre esta região que está no sudoeste do país. Ao fazer isso, informa não haver legislação específica sobre a multisseriação e que as normas do governo central definiram, por exemplo, o máximo de 30 alunos por turma no que se refere ao agrupamento de 5 a 7 anos. No que se refere à enturmação de alunos de 7 a 11 anos, existem regiões que acabam ultrapassando esse limite, alegando-se falta de condições.

Os recursos despendidos pelas pequenas escolas sempre vêm à tona. Na Inglaterra, uma escola dita "economicamente viável" deve possuir entre 120 e 150 alunos. 
Isto porque, o autor exemplifica: uma escola com 20 alunos gasta cerca de 4500 libras por aluno/ano e uma escola com 118 alunos gasta 1800 libras por aluno/ano.

Destaque também é dado aos chamados clusters, ou seja, agrupamentos de duas ou mais escolas seja para fins de acompanhamento por parte do governo, seja para fins de formação, seja para fins de compartilhamento de projetos e experiências, melhoria da gestão e no planejamento conjunto. Na Cornualha, por exemplo, existem 135 escolas organizadas em clusters que variam de 2 a 9 escolas. Ressaltase, no entanto, que as condições do clima e da região geográfica da Inglaterra são favoráveis à instauração desses clusters, o que pode não acontecer em outros países.

Rule (2005) cita que, em alguns casos, há a defesa da noção de school federation, ou seja, escola federação, tendo um diretor a frente de algumas escolas. Não é incomum encontrar clusters que avançaram inclusive na preparação de materiais pedagógicos que consideram a especificidade da localidade.

Sobre o caso da Noruega, sexto estudo, Solstad (2005) explica que desde o século XVIII, a legislação educacional do país já destacava que as parish schools (escolas paroquiais) deveriam atender a crianças de 7 a 12 anos. No início do século XX, a educação no país era essencialmente rural, tendo em vista que $80 \%$ da população estavam no campo. Atualmente, a situação é inversa e apenas $20 \%$ da população localizam-se no campo.

Até 1959, existiam dois currículos: um para a escola urbana e outro para a escola rural. A partir da segunda metade do século $\mathrm{XX}$, as escolas primárias urbanas passaram a ser organizadas por single-graded e, nesse contexto, muitas escolas foram nucleadas com a garantia de transportes escolares. Sob a alegação de melhoria e equidade das oportunidades educativas, o currículo também foi padronizado para as escolas urbanas e rurais. Apenas no final da década de 1980, abriu-se espaço para que o currículo introduzisse questões relativas à cultura da localidade.

Atualmente, cerca de $35 \%$ das escolas primárias da Noruega são multisseriadas, atendendo a cerca de $12 \%$ dos alunos matriculados em escolas primárias. Solstad (2005) destaca que o número de escolas rurais caiu drasticamente no contexto de transferência de recursos do poder central para o poder local, inviabilizando a gestão das escolas por parte dos municípios e ocasionando o fechamento de muitas escolas como alternativa para o problema. 
Durante algum tempo a multisseriação foi considerada indesejável. No entanto, o autor apresenta algumas informações que caminham em direção a avanços na educação norueguesa: o Ministério da Educação do país criou um Manual para as Escolas Multisseriadas, levando em consideração o currículo nacional e os 10 anos de escolarização básica; foi criada uma Associação Nacional de Escolas Multisseriadas, que atua tanto na formação dos professores como na defesa da educação rural frente às políticas e legislações do país. Além disso, o autor destaca, ao citar uma pesquisa da década de 1990, que as pequenas escolas rurais geralmente são as que mais envolvem os pais e as comunidades nas atividades da escola.

Conforme legislação educacional da Noruega, desde 1998, o número máximo de alunos por turma é de 12 alunos com quatro ou mais idade, 18 alunos com três idades, 24 alunos envolvendo duas idades e 28 alunos envolvendo apenas uma idade (single-grade class). No entanto, em 2004, uma emenda à lei flexibilizou essa divisão, pregando que a organização deveria privilegiar as necessidades sociais dos alunos e que a mesma não deveria pautar-se pelos méritos acadêmicos, gênero ou raça. Tal flexibilização pode ser vista como positiva tanto para alunos e escolas como para a administração do sistema, tendo em vista que pode ser utilizada para ampliar o número de alunos nas turmas, gerando uma situação negativa.

Sobre a questão do tamanho das turmas, vale destacar que, no Brasil, a legislação nacional não trata especificamente da questão e deixa tal definição a cargo dos sistemas de ensino. Em virtude disso, a multisseriação, no caso brasileiro, carregada da lógica seriada, chega a enturmar alunos não apenas da faixa etária/série/ano correspondente (6 a 10), mas também alunos que passaram por processos de reprovação e evasão, sendo possível encontrar, numa mesma turma, alunos de 6 a 19 anos $^{24}$.

Solstad (2005), quanto às pesquisas sobre o desempenho dos alunos, cita que, na década de 1970, as pesquisas indicavam pouca relação entre o desempenho e o tamanho da escola. Em relação à aprendizagem social, estudos da década de 1990 mostraram que, em escolas multisseriadas, há maior propensão para o desenvolvimento da independência e do cooperativismo.

Outra questão apontada por Solstad (2005) refere-se aos incentivos dados pelo governo do país à economia e ao desenvolvimento rural. Ele enfatiza que,

24 Fazemos referência aos dados de pesquisa em desenvolvimento, citada anteriormente, coordenadora pela autora. 
enquanto na Finlândia e na Suécia tais incentivos permanecem, isso não tem acontecido na Noruega, o que pode fortalecer o processo de fechamento das escolas como consequência da falta de investimento do campo.

Por fim, o autor destaca algumas alternativas positivas para o cenário, quais sejam: school clusters, ou seja, escolas trabalhando em conjunto para melhoria da gestão e do planejamento; e eletronic networking, utilizando-se de redes para, inclusive, ampliar as oportunidades curriculares dos alunos.

Sigpórsson e Jónsdóttir (2005) apresentam a realidade da educação na Islândia, sétimo e último estudo europeu, onde existem 180 escolas que oferecem o ensino obrigatório (6 aos 16 anos), sendo que 60 delas são classificadas em pequenas escolas com menos de 120 alunos.

Os autores salientam que, na história da educação rural da Islândia, existiram as chamadas "escolas viajantes" (traveling schools), que se constituíam de professores que viajavam de fazenda em fazenda, em cada qual permaneciam durante algumas semanas para ensinar as crianças de uma determinada região. Ao longo do século XX, os internatos (boarding schools), passaram a substituir as escolas viajantes.

Conforme os autores, são raras as escolas rurais com mais de 80 alunos ou com menos de 20. Geralmente, as escolas com cerca de 80 alunos atendem alunos na faixa etária de 6 a 16 anos e as escolas menores, com cerca de 20 alunos, atendem apenas a faixa etária de 6 a 12 anos ou 14 anos, impulsionando os alunos a concluírem a escolarização obrigatória em escolas maiores de outras regiões.

Quanto ao desempenho dos alunos, um estudo não oficial mostrou que não existem diferenças entre o desempenho de alunos de pequenas e grandes escolas, e sim, uma pequena diferença a favor de alunos que estudam na capital em relação a áreas do país.

Por fim, os autores fazem indicações quanto à necessidade de envolvimento da comunidade na escola e de fortalecimento dos school clusters. Destacam ainda o fato de que as grandes escolas estão começando a olhar mais para as escolas pequenas, nas suas estratégias de atendimento individualizado do aluno, como é o caso do multi-age teaching. 
Após a análise dos estudos apresentados sobre a multisseriação, podem ser elencadas algumas considerações principais:

A multisseriação, em países desenvolvidos, não é compreendida como um elemento negativo a priori. Os problemas ocasionados no interior das multigrade schools não ocorrem por sua lógica multigraduada.

A escola rura ${ }^{25}$ não é negada pela população ou pelos profissionais da educação por ser multisseriada. A negação é contra problemas do próprio sistema educativo que privilegia questões de ordem econômica, secundarizando questões mais relevantes de ordem pedagógica.

Defende-se claramente a manutenção da escola rural como espaço de aprendizagem da comunidade como um todo e, qualquer decisão relativa ao seu futuro deve, necessariamente, passar pela comunidade.

São evidenciados avanços de escolas que procuram trabalhar coletivamente por meio de troca de experiências, inclusive investindo-se em processos formativos e produção de materiais.

\section{A Multisseriação em Países em Desenvolvimento}

Dentre os estudos que analisam a multisseriação em países em desenvolvimento, destacamos: Little (1995) que apresenta experiências de países como Peru, Colômbia, Zâmbia e Sri Lanka; McEwan (2008) que apresenta as experiências da Colômbia, do Chile e da Guatemala; Aksoy (2008) que traz a experiência da Turquia; Mulkeen e Higgins (2009) que analisam as experiências de Uganda, Senegal e Gambia; Brown (2010) que apresenta a experiência da África do Sul. Para este artigo, optou-se por dar destaque ao primeiro estudo.

McEwan (2008) destaca que as reformas educacionais da América Latina passaram a considerar as escolas multisseriadas. A experiência da Escuela Nueva da Colômbia foi uma das precursoras dessa preocupação no campo da política educacional, seguida pela experiência da Nueva Escuela Unitaria da Guatemala e da MECE-Rural do Chile. A Escuela Nueva da Colômbia existe desde a década de 1975 e, durante sua existência, recebeu apoio financeiro da Agência dos Estados Unidos para o Desenvolvimento Internacional - USAID,

25 Utilizamos o termo educação rural para melhor traduzir as experiências citadas. No entanto, no Brasil, o termo "educação do campo" tem sido largamente utilizado para abarcar inclusive o rural. 
do Banco Interamericano de Desenvolvimento e do Banco Mundial. A Nueva Escuela Unitaria da Guatemala surgiu em 1993 e também contou com recursos da USAID. No Chile a MECE-Rural foi implantada em todo o país em 1996.

Conforme o autor, as três experiências apresentam características de implementação diferentes entre si, embora assemelhem-se em outras. As reformas implementadas, diante dos problemas e dificuldades da multisseriação, destacaram a necessidade de implantar ações que contemplassem os seguintes elementos: formação específica aos professores que trabalham em escolas multisseriadas; fornecimento de materiais específicos aos professores e aos alunos; produção de formas de interação desses profissionais com outros, minimizando o isolamento de tais escolas; compreensão do aluno como sujeito ativo no processo de aprendizagem; avaliação do aluno baseada em competências. Além disso, no caso da Colômbia e da Guatemala, os programas destacaram a necessidade de envolvimento das comunidades no trabalho escolar, bem como a criação de comitês de participação dos alunos na gestão da escola.

$\mathrm{O}$ autor lembra que tais reformas e prescrições fazem parte de recomendações de organizações internacionais, como UNESCO e Banco Mundial, e são compreendidas como estratégias para o alcance dos chamados Objetivos de Desenvolvimento do Milênio, divulgados pela Organização das Nações Unidas (ONU).

Para ilustrar a abrangência da multisseriação, no Chile, por exemplo, existem 8.727 escolas que oferecem o ensino primário ( $1^{\circ}$ ao $8^{\circ}$ ano). Destas, $57 \%$ estão localizadas na área rural, atendendo $17 \%$ dos alunos do ensino primário; $86 \%$ das escolas urbanas têm oito ou mais salas de aula e nenhuma é multisseriada; $47 \%$ das escolas rurais possuem apenas uma sala de aula e 100\% dessas são multisseriadas; $22 \%$ das escolas rurais possuem duas ou três salas de aula e destas, 90\% são multisseriadas (MCEWAN, 2008).

O mesmo autor ressalta ainda que as reformas implantadas nas escolas multisseriadas nos países analisados defendem que há uma potencialidade embutida na relação entre alunos de idades diferentes, evocando que isso pode ser benéfico para o aprendizado dos mesmos.

Acreditamos que, no âmbito político-pedagógico, a principal discussão da multisseriação tem sido como desenvolver um currículo que considere os sujeitos/alunos nas suas especificidades, na sua cultura, na sua condição, na sua 
diversidade. Ou seja, o principal questionamento é: como o professor trabalha com diferentes sujeitos de diferentes idades, matriculados em distintos anos de escolarização num mesmo espaço e, muitas vezes, com parcos recursos e pouca formação? Quais as suas estratégias para lidar com essa diversidade?

Muitas pesquisas que analisam a prática docente em salas multisseriadas acabam por visualizar currículos que tendem a transportar a seriação para a multisseriação, ou seja, os alunos são divididos conforme a faixa etária/ano de escolarização e recebem atividades diferenciadas por parte do professor e este disponibiliza tempos específicos para atendimento. Muitas políticas e programas destinados à multisseriação surgem justamente a partir da preocupação com esse formato e buscam elaborar estratégias e materiais específicos para alunos e professores, muitos deles centrando tais materiais no que chamam de aprendizagem ativa.

No contexto brasileiro, o Programa Escola Ativa, herança do Escuela Nueva da Colombia, foi muito criticado pela sociedade civil, notadamente, pelos movimentos sociais e pelas Universidades. Por vezes, a crítica ao Programa foi também a crítica à multisseriação. Mais recentemente, principalmente com a extinção do Programa, ponderações sobre a própria existência da multisseriação ganharam destaque.

\section{Conforme o Fórum Nacional de Educação do Campo}

As posições sobre a multisseriação são polêmicas e de crítica. Reconhecemos, porém que a escola multisseriada é uma realidade na educação no e do campo que não pode ser ignorada. Além disto, existem outros argumentos que nos fazem considerar essa forma de organização escolar ainda necessária no campo. São eles: toda a criança tem direito a estudar próxima à sua casa $\mathrm{e}$ de seus familiares; o transporte escolar é demasiado perigoso para crianças pequenas e o cansaço dele advindo é um agravante para a aprendizagem; estas escolas podem/devem se organizar de forma a superar a seriação e a fragmentação do conhecimento, oportunizando um trabalho por ciclos de aprendizagem; estas escolas constroem e mantêm uma relação de reciprocidade, de coletividade, de referência cultural e de organização social na comunidade em que estão inseridas (FÓRUM NACIONAL DE EDUCAÇÃO DO CAMPO, 2011, p. 1). 
Do ponto de vista da avaliação de programas e políticas que focalizam a multisseriação, McEwan (2008) faz referência a pesquisas que investigam seu processo de implementação. Tais pesquisas focalizam, por exemplo, se materiais específicos produzidos para determinado programa estão chegando às escolas; se os professores estão tendo acesso à formação específica e se esta produz efeitos nas estratégias docentes na sala de aula. Quanto a isso, afirma-se que tais políticas e programas não foram implementadas na sua totalidade, seja na Colômbia, na Guatemala ou no Chile.

No caso brasileiro, as muitas críticas sobre o processo de implementação do Programa Escola Ativa fazem referência à sua concepção e origem, articuladas ao pensamento escolanovista, com raras associações aos anseios das populações do campo, bem como à sua operacionalização, tendo em vista morosidades no fornecimento de materiais e no processo de formação de professores. (FONEC, 2011)

McEwan (2008) também apresenta estudos que avaliam o desempenho dos estudantes em turmas multisseriadas dos três países em questão, tecendo considerações e problematizando tais pesquisas do ponto de vista metodológico, e afirmando a falta de tradição da América Latina no uso de testes longitudinais na pesquisa de avaliação. Apesar disso, o autor assevera que, na Colômbia, evidenciaram-se resultados positivos no desempenho dos alunos do ensino primário com a adoção da Escuela Nueva.

Diante do trabalho de McEwan (2008) é possível elencar algumas considerações a respeito da multisseriação:

A multisseriação é vista como elemento negativo a priori. Isto porque a lógica é a mesma da seriação e, a partir disso, buscam-se novos elementos e novas metodologias que viabilizem a sua manutenção sem alteração das condições dos sistemas educativos.

A organização multisseriada é rotulada como forma de organização indesejável por parte da sociedade e por parte dos profissionais da educação, pois está fincada em problemas históricos dos sistemas educacionais.

Em vários países, a multisseriação associou-se a currículos centrados no aluno e em metodologias pautadas na aprendizagem individualizada, muitas vezes, sem a garantia das condições mínimas de infraestrutura. 


\section{Considerações Finais}

As pesquisas e experiências em países em desenvolvimento e desenvolvidos mostram claras diferenças, quanto à concepção e ao tratamento dado às escolas multisseriadas. Parece haver uma relação intrínseca entre as condições materiais da escola construídas historicamente e o direito à educação. Apesar de o discurso sobre o fechamento das escolas do campo articular-se à lógica econômica, tanto em países desenvolvidos como em países em desenvolvimento, há evidências de que a multisseriação, como forma de organização escolar, no primeiro caso, não se atrelou a um empobrecimento da oferta educacional. Já em países em desenvolvimento, como no caso brasileiro, a multisseriação, articulada à oferta educacional tardia às populações do campo, assim o fez de maneira empobrecida, a começar pelas condições materiais das próprias escolas.

Isso demonstra a importância de entender a multisseriação, ou melhor, o multigrade teaching ${ }^{26}$, como forma de organização que não deve ser vista, a priori, como um mal, embora muitos a tratem assim, sob pena de induzirmos à lógica de que bastaria a eliminação da multisseriação para acabarmos com os problemas existentes nas atuais escolas.

Se a multisseriação passa a ser entendida como um direito à educação e que, portanto, possibilita a alunos de uma determinada localidade o acesso aos bens socialmente construídos, ao exercício da cidadania, à socialização, ao desenvolvimento individual, os sistemas de ensino passam a formular estratégias e políticas que deem conta desse direito. Partimos da necessidade, portanto, não da multisseriação, mas do direito. Esse direito tem sido administrativamente tratado como "multisseriação". A questão é: como vamos tratar esse direito pedagogicamente? O desafio, portanto, não é como podemos acabar com a multisseriação, rumo à seriação, discurso vazio muito em voga e que esconde muitas vezes a eliminação do único espaço social que existe no campo: a escola pública. Até porque, na prática, "as escolas multisseriadas já são a materialização da seriação no território do campo" (MORAES et al, 2010, p. 401).

Objetivamente, o grande desafio é como garantir que todos os sujeitos, da cidade ou do campo, organizados em série, multissérie ou outra forma existente ou que venhamos a criar, tenham o direito a uma educação de qualidade e usufruam plenamente esse direito. Na expressão de Arroyo (2011), "respeitar organizando convíviosaprendizagens por tempos humanos vai além da lógica seriada e multisseriada”. (p. 13)

26 Tendo em vista que o termo em inglês não se associa necessariamente à seriação. 


\section{Referências}

AKSOY, N. Multigrade schooling in Turkey: an overview. International Journal of Educational Development, [S.1.], v. 6, n. 28, p. 218-228, 2008.

ARROYO, M. G. Currículo, território em disputa. Petrópolis, RJ: Vozes, 2011.

Escola: terra de direitos. In: HAGE, S. M.; ANTUNES-ROCHA, M. I. (Org.) Escola de Direito: reinventando à escola multisseriada. Belo Horizonte: Autêntica, 2010.

ARROYO, M. G; CALDART, R. S.; MOLINA, M. C. (Org.). Por uma educação do campo. Petrópolis, RJ: Vozes, 2009.

BRASIL. Ministério da Educação. Grupo de Trabalho de Educação do Campo. Referências para uma política nacional de educação do campo: Caderno de Subsídios. Brasília, DF: MEC, 2003.

Conselho Nacional de Educação. Resolução CNE/CEB nº. 1, de 03 de abril de 2002. Institui Diretrizes Operacionais para a Educação Básica nas Escolas do Campo. Diário Oficial da União, Brasília, DF, 9 de abril de 2002. Seção 1, p. 32. Disponível em: <http://www.red-ler.org/directrizes-educacao-campo.pdf>. Acesso em: 27 jan. 2014.

Resolução CNE no 02, de 28 de abril de 2008. Estabelece as Diretrizes Complementares, Normas e Princípios para o Desenvolvimento de Políticas Públicas de Atendimento da Educação Básica do Campo. Diário Oficial da União, Brasília, DF, 29 de abril de 2008, Seção 1, p. 81. Disponível em:<http://pfdc.pgr. mpf.gov.br/atuacao-e-conteudos-de-apoio/legislacao/educacao/educacao-rural/ resolucao_MEC_2.08>. Acesso em: 25 jun. 2012.

BROWN, B. A. Teachers' Accounts of the Usefulness of Multigrade Teaching in Promoting Sustainable Human-Development Related Outcomes in Rural South Africa. Journal of Southern African Studies, [S.1.], v. 36, n. 1, mar. 2010. Disponível em: <http://www.tandfonline.com/doi/pdf/10.1080/03057071003607428>. Acesso em: 25 jun. 2012. 
CARDOSO, M. A.; JACOMELI, M. R. M. Considerações sobre as Escolas Multisseriadas: estado da arte. Revista de Educação Educere, Cascavel/PR, v. 5, n. 9, p. 267-290, jan./jun. 2010.

CARVALHO et al. Educação do Campo no contexto do semiárido: tessitura de um processo. In: HAGE, S. M.; ANTUNES-ROCHA, M. I. (Org.) Escola de Direito: reinventando a escola multisseriada. Belo Horizonte: Autêntica, 2010, p. 285-299.

EVANS, A. Small Rural Schools: a Welsh perspective. In: SIGSWORTH, A.; SOLSTAD, K. J. Small Rural Schools: a small inquiry. Cornwall: Interskola, 2005, p. 6-17. Disponível em: <http://www.hinesna.no/system/files/skriftserie/64. pdf $>$. Acesso em: 25 jun. 2012.

FAGUNDES, J.; MARTINI, A. C. Políticas educacionais: da escola Multisseriada à escola nucleada. Revista Olhar de professor, Ponta Grossa, v. 6, n. 1, p. 99-118, 2003. Disponível em: <redalyc.uaemex.mx/pdf/684/68460108.pdf>. Acesso em: 25 jun. 2012.

FÓRUM NACIONAL DE EDUCAÇÃO DO CAMPO. Nota Técnica sobre o Programa Escola Ativa: análise crítica. Disponível em: <http://www.gepec.ufscar. br/textos-1/legislacao1>. Acesso em: 25 jun. 2012.

FREITAS, L. C. Ciclos, seriação e avaliação: confrontos de lógicas. São Paulo: Moderna, 2003.

GORDON, W.; LOKISSO, A.; ALLEN, J. Enhancing the effectiveness of single-teacher schools and multi-grade classes: synthesis of case studies. [S.1]: UNESCO, 1997. Disponível em: <http://unesdoc.unesco.org/Ulis/cgi-bin/ulis. $\mathrm{pl}$ ?catno=125917\&set=4FE8938E_1_390\&gp=0\&lin=1\&ll=s.>. Acesso em: 25 jun. 2012.

HAGE, S. M. (Org.). Educação do Campo na Amazônia: retratos de realidade das escolas multisseriadas do Pará. Belém: Gráfica e Editora Gutemberg Ltda, 2005.

HAGE, S. M; ANTUNES-ROCHA, M. I. (Org.) Escola de Direito: reinventando a escola multisseriada. Belo Horizonte: Autêntica, 2010. 
LEMOS, M. M. de. The Effectiveness of Multi-Age Grouping: an Australian study. 2001. Disponível em: <http://www.nfer.ac.uk/nfer/PRE_PDF_Files/01_25_05. pdf. $>$. Acesso em: 25 jun. 2012.

LITTLE, A. Learning and teaching in multigrade settings: paper prepared for the UNESCO 2005 EFA Monitoring Report. 2005. Disponível em: <http:// siteresources.worldbank.org/INTINDIA/4371432-1194542398355/21543231/ LearningandTeachinginMulti-Gradeclassrooms.pdf>. Acesso em: 25 jun. 2012.

Multigrade teaching: a review of practice and research. London: Overseas Development Administration, 1995.

MARIANO, L. T.; KIRBY, S. N. Achievement of students in Multigrade Classrooms: evidence from the Los Angeles Unified School District. Santa Monica: Institute of Education Sciences; Rand Education, 2009. Série Working Papers. Disponível em: <http://www.rand.org/pubs/working_papers/WR685. html>. Acesso em: 25 jun. 2012.

MASON, D. A.; BURNS, R. H. Simply no worse and simply no better, may simply be wrong: a critique of Veenman's conclusion about multigrade classes, Review of Educational Research, [S.1], v. 66, n. 3, p. 307-322, 1996. Disponível em: <http://rer.sagepub.com/content/66/3/307.abstract>. Acesso em: 25 jun. 2012.

MCEWAN, P. J. Evaluating multigrade school reform in Latin America. Comparative Education, [S.1.], v. 44, n. 4, p. 465-483, nov. 2008. Disponível em: $<$ http://www.wellesley.edu/Economics/mcewan/PDF/evaluating.pdf $>$. Acesso em: 25 jun. 2012.

MORAES, E. et al. Transgredindo o paradigma (multis)seriado nas escolas do campo. In: HAGE, S. M.; ANTUNES-ROCHA, M. I. (Org.) Escola de Direito: reinventando a escola multisseriada. Belo.Horizonte: Autêntica, 2010, p. 399-416.

MULKEEN, A. G.; HIGGINS, C. Multigrade Teaching in Sub-Saharan Africa: lessons from Uganda, Senegal, and The Gambia. Washington, D.C.: The World Bank, 2009. 
MULRYAN-KYNE, C. Small rural schools: an Irish perspective. In: SIGSWORTH, A.; SOLSTAD, K. J. Small Rural Schools: a small inquiry. Cornwall: Interskola, 2005, p. 24-29. Disponível em: <http://www.hinesna.no/ system/files/skriftserie/64.pdf>. Acesso em: 25 jun. 2012.

PARENTE, C. da M. D. A construção dos tempos e espaços escolares: possibilidades e alternativas plurais. 2006. 206 f. Tese (Doutorado em Educação) -Universidade Estadual de Campinas, Campinas, 2006. Disponível em: $<\mathrm{http}: / /$ www.bibliotecadigital.unicamp.br/document $/$ ?code $=$ vtls000390970\&opt=1.>. Acesso em: 25 jun. 2012.

PARENTE, C. da M. D; MARCHELLI, P. S.; SANTANA, S.; O Programa Escola Ativa em Sergipe e o processo de formação dos professores-multiplicadores: contribuições ao (re)conhecimento da realidade da educação no/do campo. In: PARENTE, C. M. D.; PARENTE, J. M. (Org.) Avaliação, Política e Gestão da Educação. São Cristóvão: Editora UFS, 2011, p. 157-178.

PARENTE, C. da M. D; SANTANA, S. Concepções e Práticas Pedagógicas em Escolas Multisseriadas: contribuições de um estudo de caso. In: SEMINÁRIO NACIONAL DE POLÍTICA E GESTÃO DA EDUCAÇÃO, 2., 2012, ItabaianaSE. Anais... Itabaina-SE: Grupo de Pesquisa APOGEU/UFS, 2012.

PRIDMORE, P. Adapting the primary school curriculum for multigrade classes: a 5-step plan and an agenda for action. Journal of Curriculum Studies, [S.1], v. 39, n. 1, p. 559-576, 2007. Disponível em: <http://eprints.ioe.ac.uk/3749/1/ Pridmore2007Adapting559.pdf>. Acesso em: 25 jun. 2012.

RULE, T. Rural schools: an English perspective. In: SIGSWORTH, A.; SOLSTAD, K. J. Small Rural Schools: a small inquiry. Cornwall: Interskola, 2005. p. 32-41. Disponível em: $<$ http://www.hinesna.no/system/files/skriftserie/64.pdf>. Acesso em: 25 jun. 2012.

SIGPÓRSSON, R.; JÓNSDÓTTIR, P. B. Small rural schools: an Icelandic perspective. In: SIGSWORTH, A.; SOLSTAD, K. J. Small Rural Schools: a small inquiry. Cornwall: Interskola, 2005. p. 51-58. Disponível em: $<$ http://www. hinesna.no/system/files/skriftserie/64.pdf>. Acesso em: 25 jun. 2012. 
SIGSWORTH, A.; SOLSTAD, K. J. Small Rural Schools: a small inquiry. Cornwall: Interskola, 2005. Disponível em: <http://www.hinesna.no/system/ files/skriftserie/64.pdf>. Acesso em: 25 jun. 2012.

SOLSTAD, K. J. Small rural schools: a Norwegian perspective. In: SIGSWORTH, Alan; SOLSTAD, Karl Jan. Small Rural Schools: a small inquiry. Cornwall: Interskola, 2005. p. 42-50. Disponível em: <http://www.hinesna.no/system/files/ skriftserie/64.pdf>. Acesso em: 25 jun. 2012.

SÖRLIN, I. Small Rural Schools: a swedish perspective. In: SIGSWORTH, A.; SOLSTAD, K. J. Small Rural Schools: a small inquiry. Cornwall: Interskola, 2005. p. 18-23. Disponível em: <http://www.hinesna.no/system/files/skriftserie/64.pdf>. Acesso em: 25 jun. 2012.

SYVÄNIEMI, U. Small Rural Schools: a finnish perspective. In: SIGSWORTH, A.; SOLSTAD, K. J. Small Rural Schools: a small inquiry. Cornwall: Interskola, 2005, p. 30-31. Disponível em: <http://www.hinesna.no/system/files/ skriftserie/64.pdf>. Acesso em: 25 jun. 2012.

VEENMAN, S. Cognitive and noncognitive effects of multigrade and multiage classes: a best evidence synthesis, Review of Educational Research, [S.1.], v. 65, n. 4, p. 319-381. 1995. Disponível em: <http://rer.sagepub.com/content/65/4/319. abstract>. Acesso: 25 jun. 2012.

Recebido em: 04/07/2012

Aceito para publicação em: 27/07/2013 


\section{Multiseried Schools: the international experience and reflections for the Brazilian case \\ Abstract}

The study systematizes researches and experiences of multiseried teaching in developed and developing countries by means of an international literature review that analyzes the political-pedagogical options. It emphasizes that the multiseried teaching, in Brazil, is the result of a necessity, not an educational option. However, the multiseried school originated from necessity must advance to search for educational alternatives. Understanding the several directions of the political and pedagogical options in any form of school organization, we argue that the Brazilian educational policy must give up the simple denial of multiseried teaching, and to investigate experiences and build alternatives to ensure access to quality education to all. Keywords: Multiseried school. Educational policy. Countryside education.

\section{Escuelas multigrado: experiencia internacional y reflexiones sobre el caso brasileño Resumen}

El presente estudio sistematiza la investigación y experiencia de la enseñanza multigrado en países desarrollados y en desarrollo a través de una revisión de la literatura internacional, además analiza las opciones político-pedagógicas desarrolladas en las últimas décadas. Es evidente que la enseñanza multigrado, en Brasil, resulta de una necesidad y no de una opción pedagógica. De todos modos, a pesar de originarse de una necesidad, debe avanzar y buscar alternativas pedagógicas. Abarcando las múltiples direcciones de las opciones políticopedagógicas bajo cualquier forma de organización escolar, defendemos que la política educacional brasileña debe renunciar a la simple negación de las escuelas multigrado, y buscar estudiar las experiencias e invertir en la construcción de alternativas que garanticen el acceso a una educación de calidad para todos. Palabras clave: Escuela Multigrado. Política educacional. Educación de campo. 